
\title{
Reseserch Soutere \\ Clinical Characteristics of Unsustainable Vertigo In Patients With Vestibular Neuritis
}

\author{
Lu Tang \\ Nanjing Medical University \\ Weiwei Jiang \\ Nanjing Medical University \\ Xiaoshan Wang (D lidou2005@126.com ) \\ Nanjing Medical University
}

\section{Research Article}

Keywords: Peripheral vestibular vertigo, Vestibular neuritis, Video head impulse test, Vertigo, Overt saccade

Posted Date: February 4th, 2022

DOI: https://doi.org/10.21203/rs.3.rs-1217008/v1

License: @ (i) This work is licensed under a Creative Commons Attribution 4.0 International License. Read Full License 


\section{Abstract}

Background: Vestibular neuritis $(\mathrm{VN})$ is the most common peripheral cause of acute vestibular syndrome. The typical features of VN are characterized by consistent vertigo or gait instability, persisting from one day to several weeks. Canal paresis of $\geq 25 \%$ in caloric testing is traditionally considered the hallmark of VN. However, owing to the wide application of video head impulse tests (vHITs), which precisely locate affected semicircular canals, unsustainable vertigo and instability in patients with VN have attracted interest. In this article, we retrospectively analyzed the clinical features in patients with VN and episodic vertigo, aiming to expand the atypical clinical features and effective indicator of VN.

Methods: This retrospective study enrolled 57 patients with VN. Among them, patients with symptomatic (vertigo or gait instability) remission of more than 3 times per day for more than 1 hour each time were selected for unsustainable vertigo (UV) group, while subjects without significant relief period were selected for sustainable vertigo (SV) group. Demographic information, clinical manifestations and supplementary examinations of them were collected and analyzed. These patients were followed up with one year to gather prognostic information.

Results: Statistical analysis revealed that the incident rate of spontaneous nystagmus (SN) and proportion of severe vertigo (Dizziness Handicap Inventory questionnaire score $\geq 60$ ) in SV group were significantly higher than those in UV group. Pearson correlation revealed that with a longer disease course, the latency of overt saccade was shorter $\left(p<0.01, R^{2}=0.116\right)$ and the velocity of overt saccade was slower $\left(p<0.01, R^{2}=0.150\right)$ in all patients with VN. All the patients felt relief from their symptoms after two weeks of treatment. During the first year of follow-up, no vertigo or instability reoccurred.

Conclusion: This research showed that a lower incident rate of SN and proportion of severe vertigo could explain the episodic syndrome of VN. The latency and velocity of overt saccade can be promising indicators of VN prognosis. Although the pathogenesis of paroxysmal vertigo in VN remains unknown, timely treatment will reduce the risk of vestibular sequelae and emotional disturbance.

\section{Introduction}

Vestibular neuritis $(\mathrm{VN})$ is characterized by the sudden onset of consistent vertigo or gait instability. These symptoms develop acutely in minutes or hours. VN is always accompanied by nausea or vomiting; head motion intolerance; and nystagmus. The sense of imbalance and unsteadiness may linger for weeks $[1,2]$. As the second common peripheral cause of acute vestibular syndrome next to benign paroxysmal positioning vertigo, $\mathrm{VN}$ is diagnosed in $3.2 \%-9 \%$ of patients visiting clinics because dizziness [1]. VN affects males and females equally, with a peak onset age of $40-50$ years [2, 3]. Respiratory infections are often associated with this disease. Whether VN is caused by direct infection or immune reaction remains unclear [2].The leading hypothesis suggests the reactivation of human herpes simplex virus 1 in the vestibular ganglia is responsible for the in duction and progression of VN $[4,5]$. 
Inflammatory activation can lead to a systemic reaction reducing microvascular perfusion and vestibular organ infarction, thus causing the loss of vestibular function [6].

The diagnosis of $\mathrm{VN}$ is generally based on the comprehensive interpretation of clinical and laboratory findings and reasonable exclusion of other disorders [7]. Patients are suspected for VN when they have constant vertigo for days, and spontaneous horizontal-torsional nystagmus with the quick phase beating away from the lesion side [5, 8]. The supplementary examinations, such as head impulse and caloric tests, are useful tools for evaluating vestibular function [9]. Caloric tests are used in investigating the function of the horizontal semicircular canal in the low frequency range $(\sim 0.003 \mathrm{~Hz})$, in which a canal paresis of $\geq 25 \%$ is the diagnostic hallmark of VN [7]. However, calcic tests are unsuitable for evaluating the function of vertical semicircular canals. Quantitative video head impulse tests (vHITs) can accurately identify the vestibulo-ocular reflex (VOR) function of semicircular canal in a high frequency range [10-12]. With low VOR gains, patients with VN unintentionally shift their pupils to the HIT direction and then perform a corrective saccade immediately to maintain fixation. A video-oculography system can easily detect this progress, rendering vHITs more precise and better tolerated than caloric tests $[13,14]$.

In our study, 57 patients who experienced visual rotation or gait instability were finally diagnosed with VN by using vHITs. Most of them experienced prolonged imbalance or visual oscillation for days. Notably, nine patients only experienced episodic vestibular symptoms during the whole course, and two patients had unsustainable vertigo prior to the typical continuous dizziness for VN. All the patients experienced relief from their symptoms after two weeks of treatment including symptomatic treatment and physical rehabilitation. In the first year of follow-up, no patient mentioned the recurrence of vertigo or gait instability. To the best of our knowledge, data on unsustainable vertigo in patients with VN are extremely few. Our study retrospectively analyzed patients admitted to our hospital in 2018 and 2021, aiming to determine the atypical clinical features and promising indicators of $\mathrm{VN}$.

\section{Methods}

\section{Participants}

A total of 94 patients diagnosed with VN were screened for inclusion from January 2018 to April 2021. They were hospitalized in the Neurology Division Vertigo Center at Affiliated Brain Hospital of Nanjing Medical University. All subjects were inquired the condition of symptoms and completed the Chinese version of the original dizziness handicap inventory (DHI) questionnaire at their first visit. Patients who meet all of the following criteria were enrolled in this study: (1) patients had no vertigo history by complained of a sudden onset of prolonged vertigo (more than $24 \mathrm{~h}$ ), (2) patients without brain lesions according magnetic resonance imaging and diffusion-weighted imaging, (3) patients with either horizontal or vertical vHIT gain value of $<0.8$ and corrective saccades peak velocity of $>100 \%$ [15-17], and (4) patients with affected horizontal semicircular canals, vHITs showing corrective saccades on the side of slow-phase spontaneous nystagmus (SN), and caloric paresis (CP) of $>25 \%$ according to caloric examination. The following patients were excluded: (1) patients with auditory symptoms, such as hearing 
loss, tinnitus, or ear fullness on either side and (2) patients with incomplete auxiliary findings. In total, 57 patients met the inclusion criteria for this study. Among them, patients with symptomatic (vertigo or gait instability) remission of more than 3 times per day for more than 1 hour each time were selected for unsustainable vertigo (UV) group, while subjects without significant relief period were selected for sustainable vertigo (SV) group. The flow chart for screening and grouping patients is shown in Figure 1.

\section{Vestibular function test}

Vestibular function test, composed of a bilateral caloric test and VHIT examination, was performed within 5 days after the first visit. Before a caloric test, an otoscope was used in excluding contraindications, such as tympanic membrane perforation. Patients were asked to place their heads on the pillows raised by $30^{\circ}$. Each ear was irrigated with constant airflow at alternating temperature of $30^{\circ} \mathrm{C}$ and $44^{\circ} \mathrm{C}$ for 30 s. The nystagmus was recorded using an infrared video-based system (CHARTR VNG, ICS Medical Schaumburg, IL, USA). The maximum slow-phase velocity (SPV) of the nystagmus was calculated after each irrigation, and Jongkees' formula was used in determining CP.

The high-frequency VOR functions of horizontal and vertical canals were assessed using vHITs. The vHITs was applied in all subjects using ICS impulse system (Otometrics, Denmark). The system included a pair of light goggles with integrated video oculography camera and a half-silvered mirror. The mirror reflected the image of the a subject's right eye into the camera. The right eye was illuminated by a lowpower infrared light-emitting diode. A small sensor on the goggles measured head movements. All examinations were performed by a trained physician who was particularly skilled in performing neurotological tests and the vHIT. The patients were asked to gaze at an earth-paralleled target $1.2 \mathrm{~m}$ in front during the whole examination. After calibration, the horizontal canals were evaluated. The physician stood behind a patient and turned the patient's head to the left and right unpredictably at a small angle $\left(10^{\circ}-20^{\circ}\right)$ with an appropriate velocity $\left(150^{\circ}-200^{\circ}\right.$ per second). The movement of the head in the horizontal plane stimulated the lateral semicircular canals, and the movement was only in the atlantooccipital joint pivoting around the odontoid apophysis axis [18]. To evaluate the vertical canals, the physician rotated the subject's head at a $45^{\circ}$ angle relative to the trunk and the head impulse downward with stimulate the anterior canal opposite to the side of rotation, with upward head impulse will stimulate the posterior canal at the side of rotation [10]. In a full test, 20 impulses were applied to each direction [19].

\section{Statistics}

The threshold of statistical significance for differences was set $p<0.05$ for each test. The Wilcoxon rank sum test was used in the analysis of ordered categorical data. As for quantitative data, the description was expressed as mean \pm standard deviation $(\overline{\mathrm{x}} \pm s$ ). Student's t-test was used in comparing the quantitative data when they accord with a normal distribution and their variance was homogeneous. Otherwise, the Wilcoxon signed rank sum test was used. The rates of the two groups were compared 
using Chi-square test. Pearson correlation was used in analyzing the correlation between the parameters of overt saccade and disease course. Statistical analyses were performed using SPSS version 25.0 for Windows (SPSS Inc., Chicago, IL, USA).

\section{Results}

The patients were composed of 27 males versus 30 females, aged 16-83. More than half of them (63.1\%) went to a vertigo clinic within one week. Most patients $(80.7 \%)$ experienced sustainable vertigo, whereas 11 patients (19.3\%) experienced an episodic syndrome. Nine patients only had unsustainable vertigo during the whole course, whereas two patients had transient vertigo before the onset of prolonged symptoms. The detailed clinical characteristics of the subjects are shown in Table 1. The typical vHIT results of the subjects are shown in Figure 2. Statistical analysis revealed that compared to UV group, patients in SV group had significantly higher occurrence of SN and proportion of severe vertigo (DHI questionnaire score $\geq 60$ ). No significant differences were found in gender, age, disease course, prodromal infection history, impaired vestibular nerve, and bilateral VOR difference between the two groups. Despite the subgroups, Pearson correlation revealed that the latency of overt saccade was shorter $\left(p<0.01, R^{2}=0.116\right)$ and the velocity of overt saccade was slower $\left(p<0.01, R^{2}=0.150\right)$ in a longer disease course in all patients with VN. Detailed statistical results are shown in Table 2 and Figure 3.

Table 1 Clinical characteristics of all patients with vestibular neuritis. 


\begin{tabular}{|c|c|c|}
\hline & & $n \%$ \\
\hline \multirow[t]{2}{*}{ Gender } & male & $27(47.4)$ \\
\hline & female & $30(52.6)$ \\
\hline \multirow[t]{2}{*}{ Age (years) } & $\leq 65$ & $45(78.9)$ \\
\hline & $\otimes 65$ & $12(21.1)$ \\
\hline \multirow[t]{3}{*}{ Course (days) } & $\leq 7$ & $36(63.1)$ \\
\hline & $\leq 30$ & $18(31.6)$ \\
\hline & $\nabla 30$ & $3(5.3)$ \\
\hline \multirow[t]{2}{*}{ Unsustainable vertigo } & Positive & $11(19.3)$ \\
\hline & Negative & $46(80.7)$ \\
\hline \multirow[t]{2}{*}{ History of prodromal infection } & Positive & $13(22.8)$ \\
\hline & Negative & $44(77.2)$ \\
\hline \multirow[t]{3}{*}{ Vestibular symptoms } & dizziness & $16(28.1)$ \\
\hline & Oscillopsia & $42(73.7)$ \\
\hline & Instability & $35(61.4)$ \\
\hline \multirow[t]{2}{*}{ Autonomic symptoms } & Nausea & $49(86.0)$ \\
\hline & Vomiting & $43(75.4)$ \\
\hline \multirow[t]{2}{*}{ Spontaneous nystagmus } & Positive & $31(54.4)$ \\
\hline & Negative & $26(45.6)$ \\
\hline \multirow[t]{3}{*}{ Impaired vestibular nerve } & Superior & $33(57.9)$ \\
\hline & Inferior & $2(3.5)$ \\
\hline & Both & $22(38.6)$ \\
\hline \multirow[t]{3}{*}{ Compensatory saccade } & Covert & $23(40.4)$ \\
\hline & Overt & $56(98.2)$ \\
\hline & Both & $23(40.4)$ \\
\hline \multirow[t]{2}{*}{ DHI questionnaire score } & Mild to moderate $(\nabla 60)$ & $36(63.2)$ \\
\hline & Severe $(\geq 60)$ & $21(36.8)$ \\
\hline
\end{tabular}

Table 2 Statistical analysis between patients in unsustainable vertigo (UV) group and sustainable vertigo (SV) group. 


\begin{tabular}{|c|c|c|c|c|c|c|}
\hline & & UV & SV & $\begin{array}{l}t / z / x^{2} \\
\text { value }\end{array}$ & $\begin{array}{l}p \\
\text { value }\end{array}$ & OR $(95 \% \mathrm{Cl})$ \\
\hline \multicolumn{2}{|l|}{ Age (years) } & $\begin{array}{l}58.27 \pm \\
15.05\end{array}$ & $\begin{array}{l}50.83 \pm \\
15.38\end{array}$ & 1.45 & 0.15 & - \\
\hline \multicolumn{2}{|l|}{$\begin{array}{l}\text { Lantency of overt } \\
\text { saccade (ms) }\end{array}$} & $\begin{array}{l}234.44 \pm \\
42.88\end{array}$ & $\begin{array}{l}238.77 \pm \\
64.98\end{array}$ & -0.21 & 0.84 & \\
\hline \multicolumn{2}{|l|}{$\begin{array}{l}\text { Velocity of } \\
\text { overt saccade }(\% / s)\end{array}$} & $\begin{array}{l}186.18 \pm \\
38.82\end{array}$ & $\begin{array}{l}199.47 \pm \\
64.67\end{array}$ & -0.65 & 0.52 & - \\
\hline \multicolumn{2}{|l|}{$\begin{array}{l}\text { Disease course } \\
\text { (days) }\end{array}$} & $\begin{array}{l}7.00(3.00 \\
15.00)\end{array}$ & $\begin{array}{l}3.50(2.00 \\
11.00)\end{array}$ & -1.33 & 0.35 & - \\
\hline \multicolumn{2}{|l|}{$\begin{array}{l}\text { Bilateral VOR } \\
\text { difference }\end{array}$} & $\begin{array}{l}0.29(0.18 \\
0.38)\end{array}$ & $\begin{array}{l}0.29(0.14 \\
0.35)\end{array}$ & -0.69 & 0.49 & \\
\hline \multirow{2}{*}{$\begin{array}{l}\text { History of } \\
\text { prodromal infection }\end{array}$} & Positive & $3(27.3 \%)$ & $10(21.7 \%$ & 0.15 & 1.00 & - \\
\hline & Negative* & $8(72.7 \%)$ & )$^{36(78.3 \%}$ & & & \\
\hline \multirow{2}{*}{$\begin{array}{l}\text { Spontaneous } \\
\text { nystagmus }\end{array}$} & Positive & $3(27.3 \%)$ & $28(60.9 \%$ & 4.04 & 0.04 & $\begin{array}{l}4.150(0.97- \\
17.74)\end{array}$ \\
\hline & Negative* & $8(72.7 \%)$ & )$^{18(39.1 \%}$ & & & \\
\hline \multirow{3}{*}{$\begin{array}{l}\text { Impaired vestibular } \\
\text { nerve }\end{array}$} & $\begin{array}{l}\text { Superior } \\
\text { or }\end{array}$ & $6(54.5 \%)$ & $29(63.0 \%$ & 0.03 & 0.86 & - \\
\hline & inferior* & & & & & \\
\hline & Both & $5(45.5 \%)$ & )$^{17(37.0 \%}$ & & & \\
\hline \multirow[t]{2}{*}{ Gender } & $\mathrm{male}^{\star}$ & $7(63.6 \%)$ & $26(56.5 \%$ & 1.45 & 0.23 & - \\
\hline & female & $4(36.4 \%)$ & $20(43.5 \%$ & & & \\
\hline \multirow{3}{*}{$\begin{array}{l}\text { DHI questionnaire } \\
\text { score }\end{array}$} & $\begin{array}{l}\text { Mild to } \\
\text { moderate }\end{array}$ & $9(81.8 \%)$ & $27(58.7 \%$ & 4.07 & 0.04 & $\begin{array}{l}4.958(1.231 \\
-19.980)\end{array}$ \\
\hline & 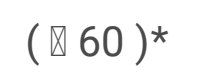 & & & & & \\
\hline & $\begin{array}{l}\text { Severe } \\
(\geq 60)\end{array}$ & $2(18.2 \%)$ & )$^{19(41.3 \%}$ & & & \\
\hline
\end{tabular}


*: the control group in Chi-square test. Statistical analysis revealed that patients with spontaneous nystagmus had significantly higher occurrence of sustainable vertigo $(p<0.05, O R=4.15)$. Besides, patients with severe vertigo ( $\mathrm{DHI}$ questionnaire score $\geq 60$ ) had significantly higher occurrence of sustainable vertigo $(p<0.05, O R=4.958)$.

\section{Discussion}

The typical manifestation of $\mathrm{VN}$ includes severe prolonged vertigo and spontaneous nystagmus. However, unstainable vertigo in VN has been reported in few studies [20]. Lemmens [21] reported that approximately a quarter of patients experienced transient dizziness before severe prolonged vertigo. Silvoniemi [1] found that $8.6 \%$ of patients with $\mathrm{VN}$ had a mild prodromal sensation of unsteadiness 1-7 days before the onset of intensive vertigo. In this study, we found that 19.3\% (11/57) of patients with VN felt an unsustainable sense of vertigo, and 3.5\% (2/57) experienced paroxysmal manifestation before the prolonged syndrome. To the best of our knowledge, no study has systematically analyzed the characteristics of paroxysmal vertigo in patients with VN. A possible reason is that previous studies usually considered that canal paresis of $\geq 25 \%$ is the hallmark of $\mathrm{VN}$, which is less sensitive and tolerable in VN diagnosis than VHITs [10]. Precise vHITs with sensitivity of up to $86.7 \%$ and specificity of $100 \%$ in VN diagnosis [22] contributed to accurate diagnosis in atypical clinical features.

Compared to patients with sustainable vertigo, those with episodic syndrome showed lower occurrence of $\mathrm{SN}$ and fairly mild clinical symptoms. The explanation might be that $\mathrm{SN}$ is the most prominent indicator of static vestibular imbalance. Previous study has found that initial degree of $\mathrm{SN}$ affects the duration of hospitalization, and VN patients with higher SN degree at the initial evaluation tended to have persistent SN [23]. VN patients with lower occurrence of SN experienced mild vestibular syndromes since their static imbalance was incompletely damaged or quickly recovered. Higher occurrence of SN leads to more sever vestibular syndromes and higher DHI questionnaire score.

In our study, patients were asked to complete the DHI questionnaire for the assessment of the behavioral and emotional status influenced by vertigo. The DHI questionnaire comprised 25 items with scores ranging from 0 and 100 points. It can be further subdivided into physical, functional, and emotional subscores [24]. Statistic results showed that compared with UV group, patients in SV group had significantly higher odds of severe vertigo (DHI questionnaire score $\geq 60$ ). In other words, the quality of life of patients with VN and persistent vertigo was considerably more affected by physical disability and psychological stress. Similarly, Nola et al. [25] have found that vertigo patients presented concomitant psychological symptoms in $56.38 \%$ of cases, and anguish was the most prevalent (47.38\%), followed by anxiety, fear, depression, and memory disorders. Compared with healthy subject, patients with vestibular hypofunctional exhibit increased anxiety and depressions [26, 27]. From this point of view, VN patients with persistent vertigo and high DHI score should receive psychological or drug intervention to prevent emotional disorders if necessary. 
As known, during head impulses while stationary targets are fixated, subjects with low vestibulo-ocular gains produced corrective saccades. Saccades are triggered in the direction of the deficient slow-phase response when the head is still moving (covert saccades) and after the head is stopped (overt saccades) $[28,29]$. Our research found that the parameters (latency and velocity) of overt saccades were negatively correlated with disease course. Given that saccade pulse amplitude adaptation is considered to be mediated by the dorsal cerebellar vermis and fastigial nucleus [30], the dynamic changes of saccades reflects the participation of central compensation in the peripheral vestibular lesion (PVL). Previous observations have found static compensation that caused by the rapid restoration of the balance among the electrical activities of bilateral vestibular nuclei complexes, developed quickly within days or weeks after PVL [31, 32]. However, dynamic compensation requires a long time given that complex sensory processes and behavioral substitution are predominant in dynamic function recovery [33]. With the recovery of the dynamic function, which are minimally dependent of the recovery of static symptoms and requires various idiosyncratic vicarious strategies, overt saccades gradually decreased because static compensation became less important [32]. Thus, saccades can also be reliable indicator of the VN onset and prognosis other than VOR.

\section{Conclusion}

Unsustainable vertigo and instability can be found in a few patients with VN. The unsustainable manifestations in VN are misdiagnosed as central vertigo due to insufficient awareness. By retrospectively analyzing the clinical characteristics of patients with $\mathrm{VN}$ and paroxysmal vertigo, our research expanded the atypical clinical features of $\mathrm{VN}$ and promising indicators of $\mathrm{VN}$ prognosis. Although the pathogenesis of paroxysmal vertigo in $\mathrm{VN}$ remains unknown, timely treatment will reduce the risk of vestibular sequelae and emotional disturbance.

\section{Abbreviations}

VN: Vestibular neuritis; HIT: Head impulse tests; VOR: Vestibulo-ocular reflex, DHI: Dizziness handicap inventory; SN: Spontaneous nystagmus; CP: Caloric paresis; UV: Unsustainable vertigo; SV: Sustainable vertigo; SPV: Slow-phase velocity; PVL: Peripheral vestibular lesion; VNC: vestibular nuclei complex; HC: Horizontal semicircular canal; AC: Anterior semicircular canal; PC: Posterior semicircular canal.

\section{Declarations}

\section{Ethics approval and consent to participate}

This study was approved by the Ethics Committee of the Affiliated Brain Hospital of Nanjing Medical University (registration No. 2018-KY045-1). Informed consent was waived in this study by the Ethics Committee of the Affiliated Brain Hospital of Nanjing Medical University. We strictly followed the guideline of the World Medical Association Declaration of Helsinki. 


\section{Consent for publication}

Not applicable.

\section{Availability of data and materials}

All data generated or analyzed during this study are included in this published article and its supplementary information files.

\section{Competing interests}

The authors declare that the research was conducted in the absence of any commercial or financial relationships that could be construed as a potential conflict of interest.

\section{Funding}

This research did not receive any specific grant from funding agencies.

\section{Authors' contributions}

LT contributed to the conceptualization of the content, writing the preliminary version of the manuscript and interpretation of data. WWJ contributed to the conceptualization of the content, co-writing of the academic content related to neurology. XSW revised the article and approved the final manuscript before submission.

\section{Acknowledgements}

The authors would like to express their appreciation to Dr. Li Zhang, Feng Li and Xiaobing Song of the Affiliated Brain Hospital of Nanjing Medical University, for screening patients and operating the vestibular function tests.

\section{References}

1. Silvoniemi P: Vestibular neuronitis. An otoneurological evaluation. Acta Otolaryngol Suppl 1988, 453:1-72.

2. Greco A, Macri GF, Gallo A, Fusconi M, De Virgilio A, Pagliuca G, Marinelli C, de Vincentiis M: Is vestibular neuritis an immune related vestibular neuropathy inducing vertigo? J Immunol Res 2014, 2014:459048.

3. Bartual-Pastor J: Vestibular neuritis: etiopathogenesis. Rev Laryngol Otol Rhinol (Bord) 2005, 126(4):279-281.

4. Jeong SH, Kim HJ, Kim JS: Vestibular neuritis. Seminars in neurology 2013, 33(3):185-194.

5. Le TN, Westerberg BD, Lea J: Vestibular Neuritis: Recent Advances in Etiology, Diagnostic Evaluation, and Treatment. In: Vestibular Disorders. edn.; 2019: 87-92. 
6. Kassner SS, Schottler S, Bonaterra GA, Stern-Straeter J, Hormann K, Kinscherf R, Gossler UR: Proinflammatory activation of peripheral blood mononuclear cells in patients with vestibular neuritis. Audiol Neurootol 2011, 16(4):242-247.

7. Ahn SH, Shin JE, Kim CH: Final diagnosis of patients with clinically suspected vestibular neuritis showing normal caloric response. Journal of clinical neuroscience: official journal of the Neurosurgical Society of Australasia 2017, 41:107-110.

8. Karlberg ML, Magnusson M: Treatment of acute vestibular neuronitis with glucocorticoids. Otology \& neurotology: official publication of the American Otological Society, American Neurotology Society [and] European Academy of Otology and Neurotology 2011, 32(7):1140-1143.

9. Perez N, Rama-Lopez J: Head-impulse and caloric tests in patients with dizziness. Otology \& neurotology: official publication of the American Otological Society, American Neurotology Society [and] European Academy of Otology and Neurotology 2003, 24(6):913-917.

10. Alhabib SF, Saliba I: Video head impulse test: a review of the literature. Eur Arch Otorhinolaryngol 2017, 274(3):1215-1222.

11. Fetter M: Vestibulo-ocular reflex. Developments in ophthalmology 2007, 40:35-51.

12. Weber KP, MacDougall HG, Halmagyi GM, Curthoys IS: Impulsive testing of semicircular-canal function using video-oculography. Annals of the New York Academy of Sciences 2009, 1164:486491.

13. Cremer PD, Halmagyi GM, Aw ST, Curthoys IS, McGarvie LA, Todd MJ, Black RA, Hannigan IP: Semicircular canal plane head impulses detect absent function of individual semicircular canals. Brain 1998, 121 (Pt 4):699-716.

14. Jahn $\mathrm{K}$ : Vertigo and balance in children-diagnostic approach and insights from imaging. Eur $\mathrm{J}$ Paediatr Neurol 2011, 15(4):289-294.

15. Sabour S: Diagnostic Value of Video Head Impulse Test in Vestibular Neuritis: Methodological Issues. Otolaryngology-head and neck surgery: official journal of American Academy of Otolaryngology-Head and Neck Surgery 2018, 159(2):400.

16. MacDougall HG, Weber KP, McGarvie LA, Halmagyi GM, Curthoys IS: The video head impulse test: diagnostic accuracy in peripheral vestibulopathy. Neurology 2009, 73(14):1134-1141.

17. Yang CJ, Lee JY, Kang BC, Lee HS, Yoo MH, Park HJ: Quantitative analysis of gains and catch-up saccades of video-head-impulse testing by age in normal subjects. Clinical otolaryngology: official journal of ENT-UK ; official journal of Netherlands Society for Oto-Rhino-Laryngology \& Cervico-Facial Surgery 2016, 41(5):532-538.

18. Ulmer E, Bernard-Demanze L, Lacour M: Statistical study of normal canal deficit variation range. Measurement using the Head Impulse Test video system. European annals of otorhinolaryngology, head and neck diseases 2011, 128(5):278-282.

19. Fu W, He F, Zhao R, Wei D, Bai Y, Wang X, Han J: Effects of Hand Positions During Video HeadImpulse Test (VHIT) in Patients With Unilateral Vestibular Neuritis. Frontiers in neurology 2018, 9:531. 
20. Kim JS: When the Room Is Spinning: Experience of Vestibular Neuritis by a Neurotologist. Frontiers in neurology 2020, 11:157.

21. Lemmens R, Race V, Hersmus N, Matthijs G, Van Den Bosch L, Van Damme P, Dubois B, Boonen S, Goris A, Robberecht W: TDP-43 M311V mutation in familial amyotrophic lateral sclerosis. Journal of neurology, neurosurgery, and psychiatry 2009, 80(3):354-355.

22. Jorns-Haderli M, Straumann D, Palla A: Accuracy of the bedside head impulse test in detecting vestibular hypofunction. Journal of neurology, neurosurgery, and psychiatry 2007, 78(10):11131118.

23. Kim SJ, Lee HY, Lee MY, Choi JY: Initial Degree of Spontaneous Nystagmus Affects the Length of Hospitalization of Patients With Vestibular Neuritis. Otology \& neurotology: official publication of the American Otological Society, American Neurotology Society [and] European Academy of Otology and Neurotology 2020, 41(6):836-842.

24. Neupane AK, Kapasi A, Patel N: Psychometric Features of Dizziness Handicap Inventory (DHI): Development and Standardization in Gujarati Language. The international tinnitus journal 2019, 23(2):86-90.

25. Nola G, Mostardini C, Salvi C, Ercolani AP, Ralli G: Validity of Italian adaptation of the Dizziness Handicap Inventory (DHI) and evaluation of the quality of life in patients with acute dizziness. Acta otorhinolaryngologica Italica: organo ufficiale della Societa italiana di otorinolaringologia e chirurgia cervico-facciale 2010, 30(4):190.

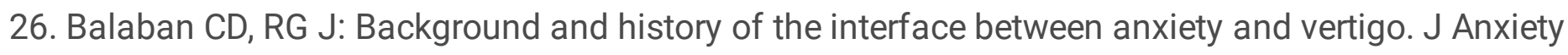
Disord 2001, 15:27-51.

27. Huppert $D$, Wuehr M, Brandt T: Acrophobia and visual height intolerance: advances in epidemiology and mechanisms. Journal of neurology 2020, 267(Suppl 1):231-240.

28. Weber KP, Aw ST, Todd MJ, McGarvie LA, Curthoys IS, Halmagyi GM: Head impulse test in unilateral vestibular loss: vestibulo-ocular reflex and catch-up saccades. Neurology 2008, 70(6):454-463.

29. Colagiorgio P, Versino M, Colnaghi S, Quaglieri S, Manfrin M, Zamaro E, Mantokoudis G, Zee DS, Ramat S: New insights into vestibular-saccade interaction based on covert corrective saccades in patients with unilateral vestibular deficits. Journal of neurophysiology 2017, 117(6):2324-2338.

30. Colnaghi S, Colagiorgio P, Versino M, Koch G, D'Angelo E, Ramat S: A role for NMDAR-dependent cerebellar plasticity in adaptive control of saccades in humans. Brain Stimul 2017, 10(4):817-827.

31. Tighilet B, Bordiga P, Cassel R, Chabbert C: Peripheral vestibular plasticity vs central compensation: evidence and questions. Journal of neurology 2019, 266(S1):27-32.

32. Lacour M: Restoration of vestibular function: basic aspects and practical advances for rehabilitation. Current medical research and opinion 2006, 22(9):1651-1659.

33. Lacour M, Helmchen C, Vidal PP: Vestibular compensation: the neuro-otologist's best friend. Journal of neurology 2016, 263 Suppl 1:S54-64.

\section{Figures}




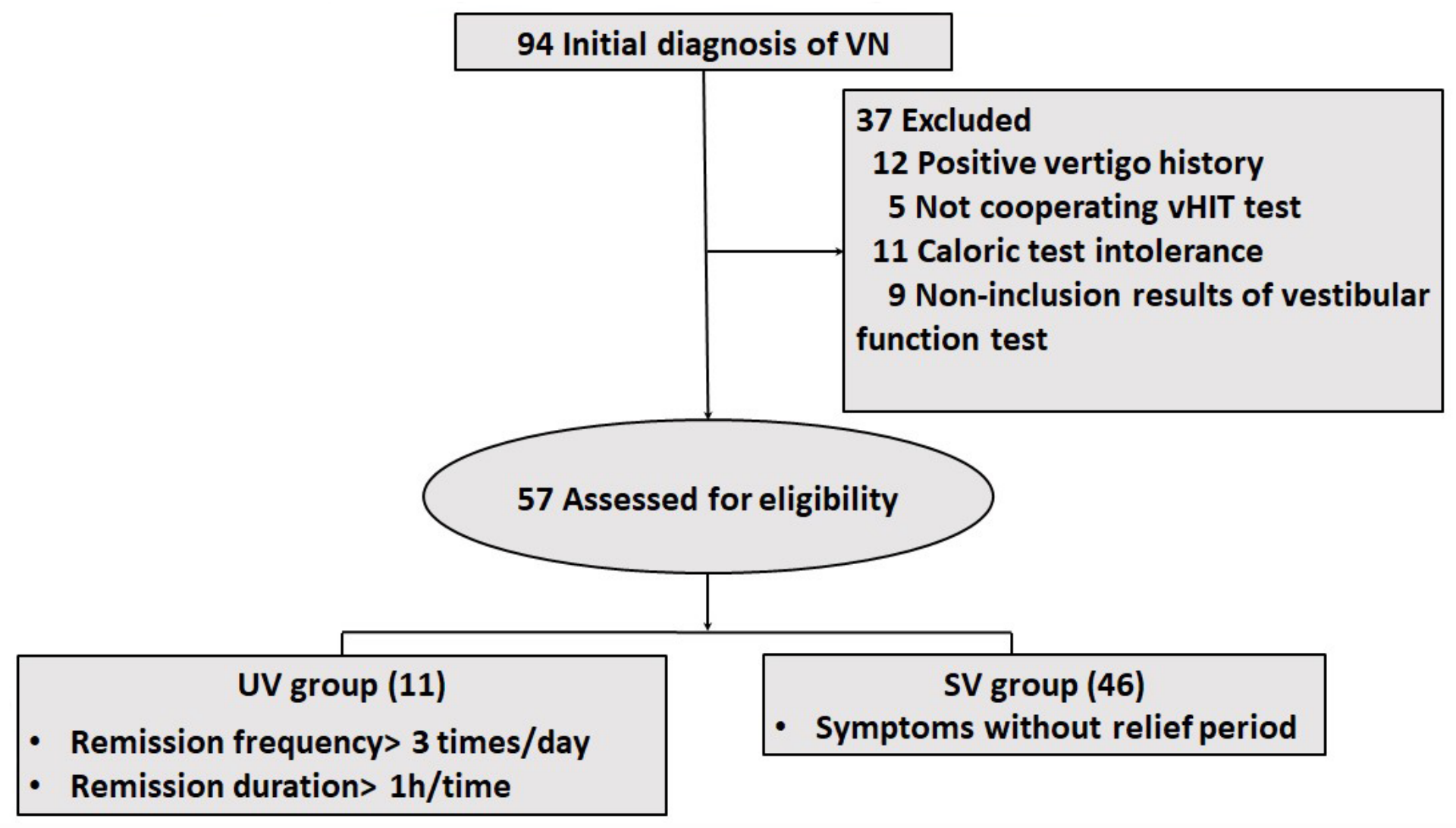

Figure 1

Flow chart for enrolling and grouping patients. 

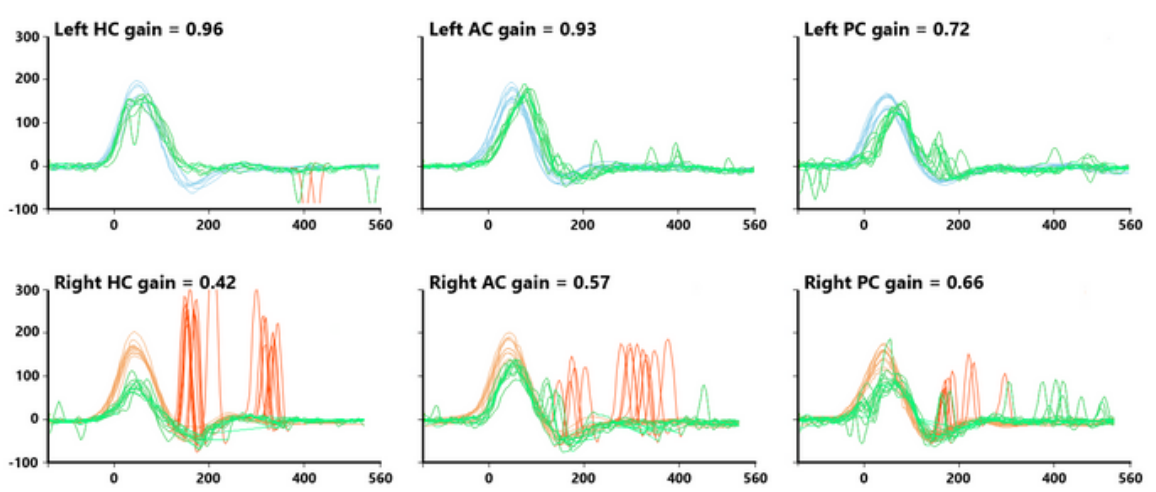

A
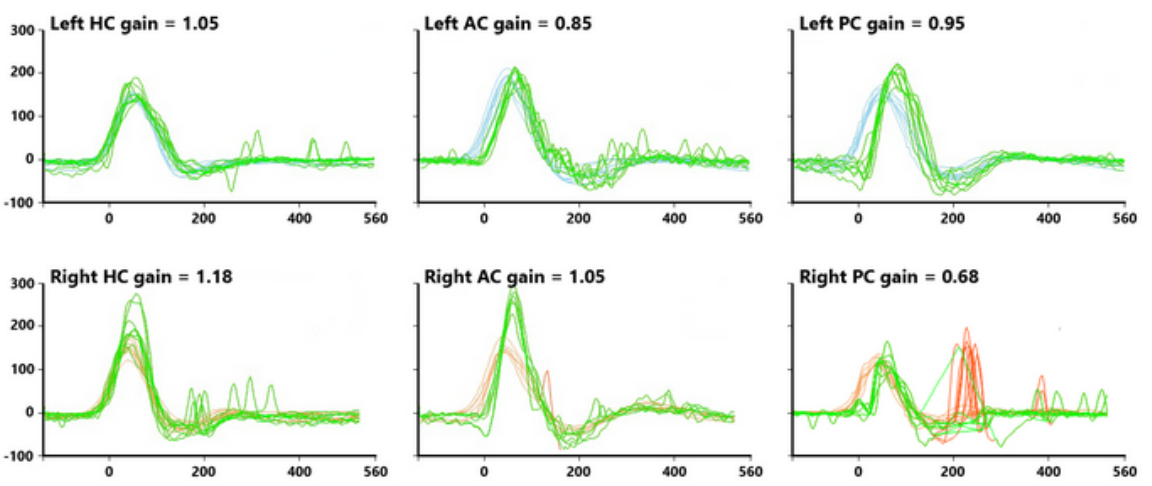

B
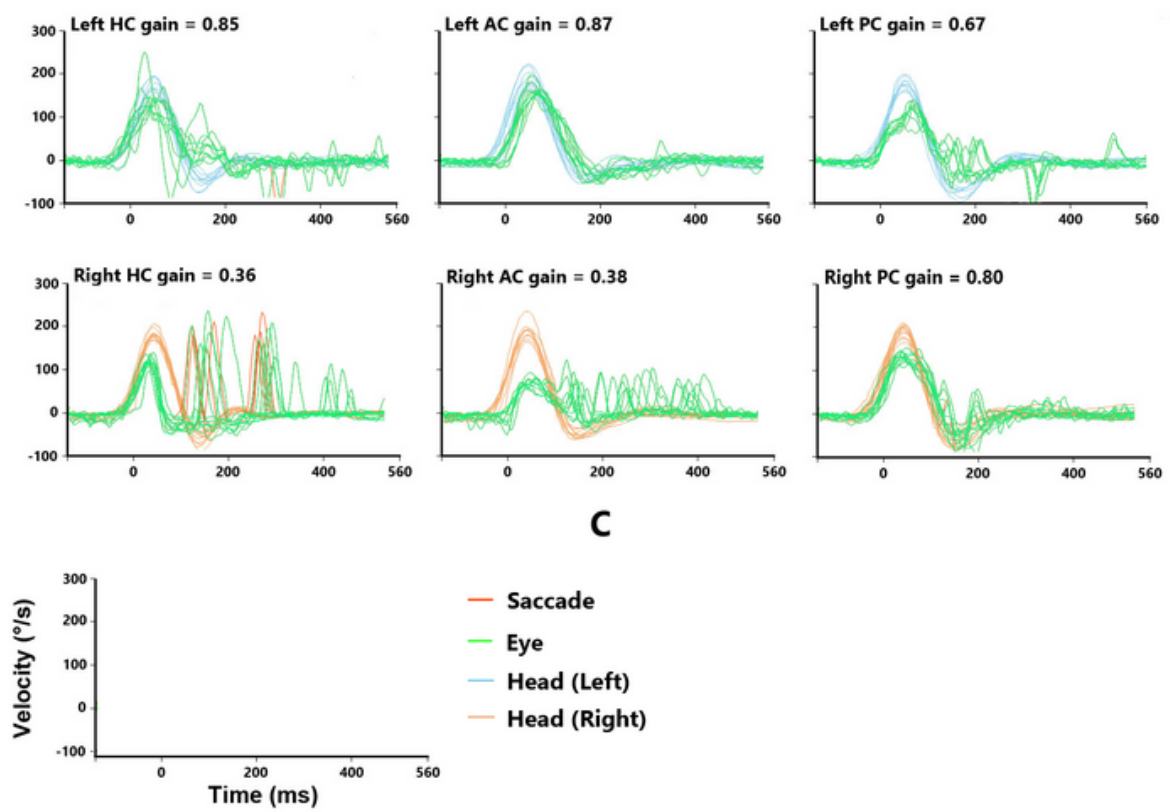

- Saccade

- Eye

- Head (Left)

- Head (Right)

\section{Figure 2}

Typical vHIT images recorded from patients with unsustainable vertigo. The sample coordinates (last row) indicate the units of vHITs.

A: A patient with damaged superior and inferior vestibular nerves. The vHITs findings showed decreased gains and corrective saccade of VOR for the right horizontal semicircular canal (HC) and vertical 
semicircular canals, including anterior and posterior semicircular canal (AC and PC).

B: A patient with inferior vestibular nerve damage. The vHIT findings showed decreased gains in VOR for the right $\mathrm{PC}$, while that for right $\mathrm{AC}$ and $\mathrm{HC}$ were normal.

C: Patient with superior vestibular nerve damage. The vHIT findings showed decreased gains of VOR for the right $\mathrm{AC}$ and $\mathrm{HC}$. The VOR for right PC was normal.
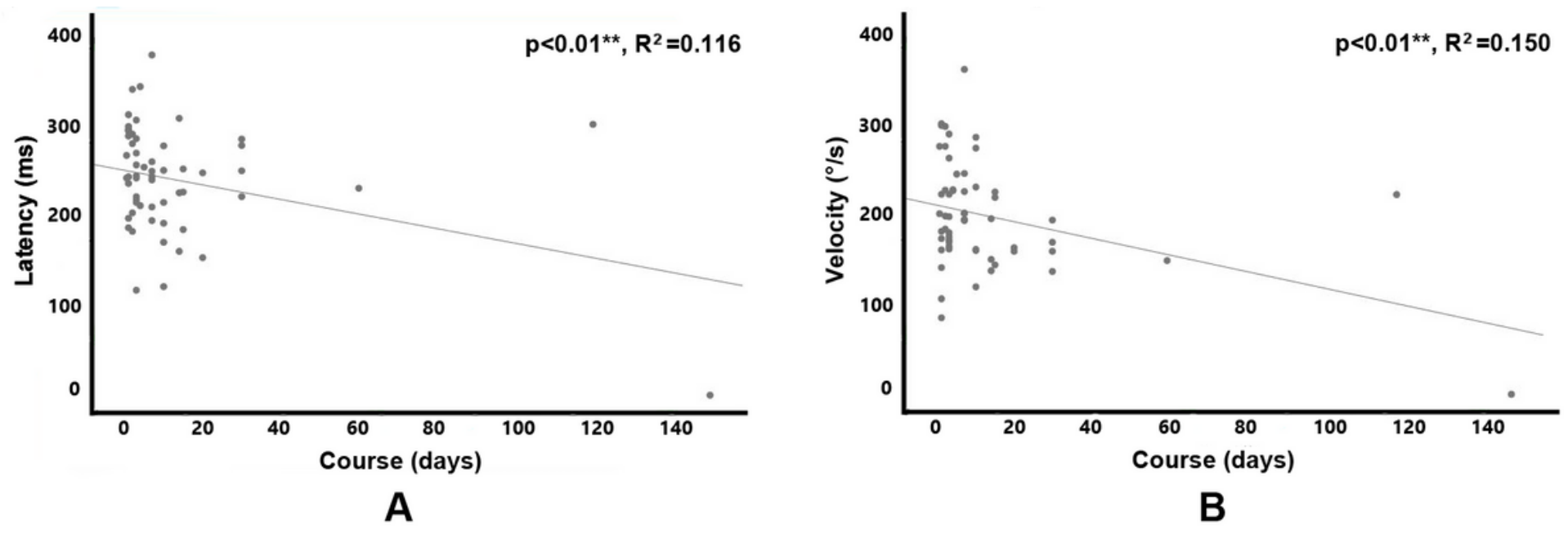

\section{Figure 3}

Pearson correlation revealed that the longer disease course is, the shorter the latency of the overt saccade $\left(p<0.01, R^{2}=0.116\right)$ and the slower the velocity of the overt saccade are $\left(p<0.01, R^{2}=0.150\right)$ in all patients with VN.

\section{Supplementary Files}

This is a list of supplementary files associated with this preprint. Click to download.

- statisticcasecontrol.pdf

- statisticcasecontrollable.pdf 